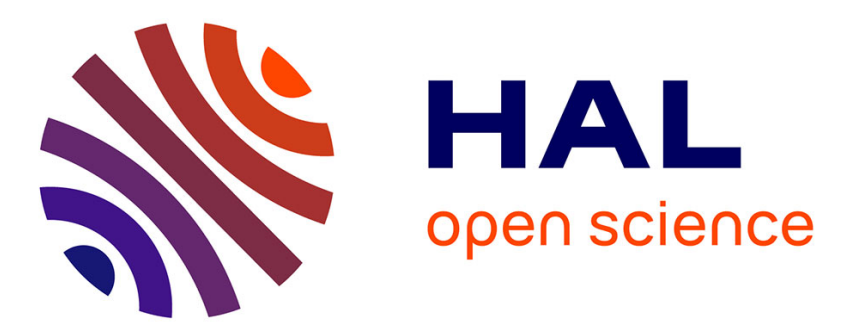

\title{
Characterization and reduction of magnetic noise due to saturation in induction machines
}

\author{
J. Le Besnerais, V Lanfranchi, Michel Hecquet, G Lemaire, E Augis, P.
}

Brochet

\section{> To cite this version:}

J. Le Besnerais, V Lanfranchi, Michel Hecquet, G Lemaire, E Augis, et al.. Characterization and reduction of magnetic noise due to saturation in induction machines. IEEE Transactions on Magnetics, 2009，10.1109/TMAG.2008.2012112 . hal-01713831

\section{HAL Id: hal-01713831 \\ https://hal.science/hal-01713831}

Submitted on 20 Feb 2018

HAL is a multi-disciplinary open access archive for the deposit and dissemination of scientific research documents, whether they are published or not. The documents may come from teaching and research institutions in France or abroad, or from public or private research centers.
L'archive ouverte pluridisciplinaire HAL, est destinée au dépôt et à la diffusion de documents scientifiques de niveau recherche, publiés ou non, émanant des établissements d'enseignement et de recherche français ou étrangers, des laboratoires publics ou privés. 


\title{
Characterization and reduction of magnetic noise due to saturation in induction machines
}

\author{
J. Le Besnerais, Student Member, IEEE, V. Lanfranchi, M. Hecquet, G. Lemaire, E. Augis, and P. Brochet
}

\begin{abstract}
This paper derives the analytical characterization of Maxwell radial vibrations due to saturation effects in induction machines, and especially in traction motors. The number of nodes and the velocity of these particular force waves are experimentally validated by visualizing some operational deflection shapes of the stator. It is shown that according to the stator and rotor slot numbers, and stator natural frequencies, these forces can be responsible for high magnetic noise levels during electrical starting and braking. A simple rule to avoid saturation magnetic noise is then proposed, and applied to an industrial motor.

A fully analytical model of the motor vibro-acoustic behavior, including saturation effects, is finally presented. Simulation results show that the new proposed motor improves magnetic noise level up to $20 \mathrm{~dB}$, whereas experiments give a $15 \mathrm{~dB}$ improvement.
\end{abstract}

Index Terms-Induction machine, saturation, magnetic noise, vibrations, Maxwell forces.

\section{NOMENCLATURE}

$b_{r} \quad$ Rotor slot opening width

$b_{s} \quad$ Stator slot opening width

$d_{f}^{r} \quad$ Rotor fictitious slot depth

$d_{f}^{s} \quad$ Stator fictitious slot depth

$f_{2} \quad$ Stator mode number 2 natural frequency

$f_{c} \quad$ PWM switching frequency

$f_{s} \quad$ Stator current fundamental frequency

$f_{m m}^{s} \quad$ Stator magnetomotive force (mmf)

$F_{0} \quad$ Stator mmf magnitude

$g \quad$ Air-gap width

$k_{a} \quad$ Integers involved in saturation permeance

Fourier series

$K_{c} \quad$ Carter coefficient

$k_{r}, k_{s} \quad$ Integers involved in slotting permeance

Fourier series

$K_{s} \quad$ Saturation factor

$p \quad$ Number of pole pairs

$P_{a} \quad$ Saturation permeance harmonics

$P_{r}, P_{s} \quad$ Rotor and stator slotting permeance harmonics magnitude

Manuscript received the 30th of October, 2008. This work was supported in part by the French Agence De l'Environnement et de la Maîtrise de l'Energie.

J. Le Besnerais is with ALSTOM Transport, and with the Laboratoire d'Electrotechnique et d'Electronique de Puissance (L2EP), Ecole Centrale de Lille, FRANCE (e-mail:jean.le_besnerais@centraliens.net).

G. Lemaire and E. Augis are with the company VIBRATEC, Ecully, FRANCE.

V. Lanfranchi is with the LEC (Laboratoire d'Electromécanique de Compiègne), UTC, Compiègne, FRANCE (e-mail: vincent.lanfranchi@utc.fr).

M. Hecquet and P. Brochet are also with the L2EP (e-mail: michel.hecquet@ec-lille.fr and pascal.brochet@ec-lille.fr).

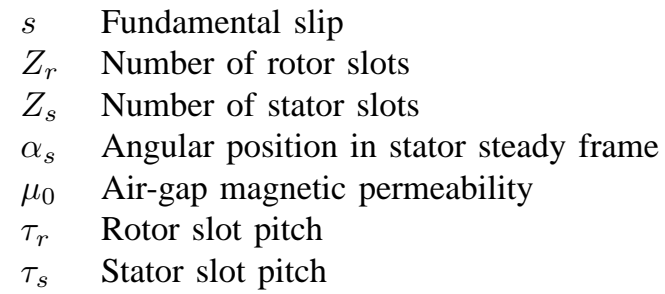

\section{INTRODUCTION}

A Coustic comfort becomes increasingly important in subways and light-rail vehicles for both passengers who can be placed close to the engine, but also for frontage residents and passers-by. As progress is being made in mechanical and aerodynamic noise reduction, the full understanding of magnetic noise generation becomes crucial. This particular source of noise, whose tonalities are penalized by IEC 60034-9 norm, is mainly due to the air-gap radial Maxwell forces which excite the stator in the audible range. Saturation effects modify the Maxwell forces spectrum, especially in starting phase where the air-gap flux is maximal in order to develop maximal torque, and can therefore create new harmful resonances.

This paper first presents the analytical characterization of Maxwell vibrations due to saturation effects, on the ground of a fully analytical vibro-acoustic model of the induction machine called DIVA. Their characteristics (velocity, number of nodes) are experimentally validated by visualizing the stator stack deflections at some given frequencies. An experimental law of the noise level increase with saturation is also established.

A simple design rule on rotor and stator slot combination in order to avoid strong resonances due to saturation is then proposed, and applied to a given motor where saturation forces create strong vibrations. Some DIVA simulations are finally run to compare the noise radiated by the tested motor and the new proposed motor, and successfully compared to experimental results.

\section{Characterization OF MAGNetic NOISE DUE TO SATURATION}

\section{A. Expression of radial Maxwell forces}

Magnetic forces can come from magnetostriction and Maxwell forces. Magnetostriction rather affects frequencies inferior to $500 \mathrm{~Hz}$ [1], [2], it is assumed not to be responsible for high pitch magnetic noise. Neglecting these magnetostrictive effects, and the tangential component of Maxwell tensor, the radial exciting pressure $P_{M}$ which is supposed to be the only magnetic noise source can be approximated by [3], [4], [5] 


$$
P_{M}=B_{g}^{2} /\left(2 \mu_{0}\right)
$$

where $B_{g}$ is the radial air-gap flux density. Assuming that the rotor is not skewed, and neglecting end-effects, this force is independent of the axial direction and can therefore only excite some circumferential modes of the stator stack, which can be modeled by an equivalent ring as a first approximation [4], [6]. Developing the magnetic pressure (1) in two-dimensional Fourier series, it can be expressed as a sum of progressive force waves of frequency $f$ and space frequency $m$ (spatial order) :

$$
P_{M}\left(t, \alpha_{s}\right)=\sum_{m, f} A_{m f} \cos \left(2 \pi f t-m \alpha_{s}+\phi_{m f}\right)
$$

A magnetic noise resonance occurs at two conditions [7]: the order $m$ of the force harmonic must be the same as the circumferential mode number of the stator (e.g. $m=2$ for the elliptical mode), and the frequency of the force harmonic must be the same as the frequency of the natural frequency of the stator mode under consideration. In variable-speed motors, this frequency match condition is more easily satisfied as the frequencies of magnetic forces due to fundamental current vary proportionally to the supply frequency $f_{s}$, and therefore sweep a wide frequency range during starting and braking. There exist an infinite number of force harmonics, but the magnitude of the vibration waves that they generate are inversely proportional to $m^{4}$ [5], so that only the lowest spatial orders forces lead to significant vibration and noise $(0$ to 4 for traction motors).

In order to predict magnetic noise resonances, one must therefore analytically calculate the Fourier development of $P_{M}$. This requires an analytical model of the air-gap radial flux density distribution, for instance a permeance / magnetomotive force (mmf) decomposition [8]. In no-load case, this decomposition can be written as [9]

$$
B_{g}=\Lambda f_{m m}^{s}=\frac{\mu_{0}}{g_{f}} f_{m m}^{s}
$$

where $g_{f}$ is the air-gap "fictitious width", i.e. the mean length of flux density lines along the air-gap, which can equal $g, g+d_{f}^{s}, g+d_{f}^{r}$ or $g+d_{f}^{s}+d_{f}^{r}$ according to the respective position of stator and rotor slots. The Fourier series expressions of both permeance and mmf distributions can be found in [10], [11], as well as the flux density spectrum resulting from their multiplication, and the Maxwell force spectrum obtained from the combination of flux density harmonics.

Schematically, any Maxwell pressure harmonic $P_{h}$ can be written in no-load sinusoidal case as

$$
P_{h}=\Lambda_{h} \Lambda_{h^{\prime}} F_{h} F_{h^{\prime}} /\left(2 \mu_{0}\right)
$$

where $\Lambda_{h}$ and $\Lambda_{h^{\prime}}$ are permeance fundamental or harmonics which can come either from stator slotting $\left(\Lambda_{s}\right)$, rotor slotting $\left(\Lambda_{r}\right)$ or their interaction $\left(\Lambda_{s r}\right), F_{h}$ and $F_{h^{\prime}}$ are stator mmf fundamental $\left(F_{0}\right)$ or harmonics $\left(F_{w}\right)$ which come from the discretized distribution of stator winding in slots.

\section{B. Saturation force waves}

All these combinations give numerous pressure waves. However, the higher their spatial order $m$ is, the lower stator static deflection is [4]. Moreover, some of them have very low magnitude as they come from the multiplication of low magnitude harmonics (e.g. a high order mmf space harmonic combined with a high order permeance harmonics gives a very low flux density harmonic). Finally, some of these harmonics have low frequencies (inferior to $400 \mathrm{~Hz}$ ), far from human's ear maximal sensitivity range.

Neglecting these force waves, one can find that they can be reduces to three main families assuming that currents are sinusoidal [12], [13]:

1) slotting force harmonics, coming from the interaction of some rotor and stator slotting permeance harmonics with twice the stator mmf fundamental (magnitude $\left.\Lambda_{s} \Lambda_{r} F_{0} F_{0} /\left(2 \mu_{0}\right)\right)$

2) "winding force" harmonics, coming from the interaction of some rotor and stator slotting permeance harmonics with the stator mmf fundamental, and with one stator mmf space harmonic (magnitude $\Lambda_{s} \Lambda_{r} F_{0} F_{w} /\left(2 \mu_{0}\right)$ )

3) saturation force harmonics, coming from the interaction of a slotting permeance harmonics with a saturation permeance harmonic, and with twice stator mmf fundamental (magnitude $\Lambda_{s r} \Lambda_{a} F_{0} F_{0} /\left(2 \mu_{0}\right)$ )

Saturation of teeth indeed flattens the air-gap flux density, which modifies the space harmonic content of Maxwell forces, and can change magnetic noise level [4]. This effect can be modelled by adding to the permeance function additional permeance harmonics due to saturation with spatial order $2 p k_{a}$ where $k_{a}$ is a positive integer [8], [14], [15], [16]:

$\Lambda_{s a t}\left(t, \alpha_{s}\right)=\Lambda\left(t, \alpha_{s}\right)+\sum_{k_{a}=1}^{\infty} \Lambda_{k_{a}} \cos \left(2 k_{a} \omega_{s} t+2 p k_{a} \alpha_{s}+\phi_{a}\right)$

where the permeance harmonics magnitude $\Lambda_{k_{a}}$ depend on the saturation factor and are inversely proportional to $k_{a}$. For $k_{a}=1$, we have for instance [14]

$$
\Lambda_{1}=\frac{\mu_{0}}{g K_{c} K_{s}} \frac{2 A_{s a t}}{1+A_{s a t}} \quad A_{s a t}=\frac{F_{s t}+F_{r t}}{F_{g}+F_{s y}+F_{r y}}
$$

where $F_{s t}$ and $F_{r t}$ are the ampere-turns in stator and rotor teeth path, $F_{s y}$ and $F_{r y}$ are the ampere-turns in stator and rotor yoke paths, and $F_{g}$ are the ampere-turns coming from the air-gap path.

The air-gap flux density distribution flatening with saturation is illustrated in Fig. 1 for $k_{a}=1$.

To obtain the analytical expression of these particular force waves, one can develop all the involved quantities (permeance and $\mathrm{mmf}$ ) in Fourier series. As saturation waves are linked to the stator mmf fundamental, the permeance harmonics expression are only needed. One can show that [17]

$$
\begin{aligned}
\Lambda_{s r}=\frac{1}{2} K_{s r}(\cos ( & \left.\left(k_{s} Z_{s}-k_{r} Z_{r}\right) \alpha_{s}+k_{r} Z_{r} \alpha_{r}\right) \\
& \left.+\cos \left(\left(k_{s} Z_{s}+k_{r} Z_{r}\right) \alpha_{s}-k_{r} Z_{r} \alpha_{r}\right)\right)
\end{aligned}
$$




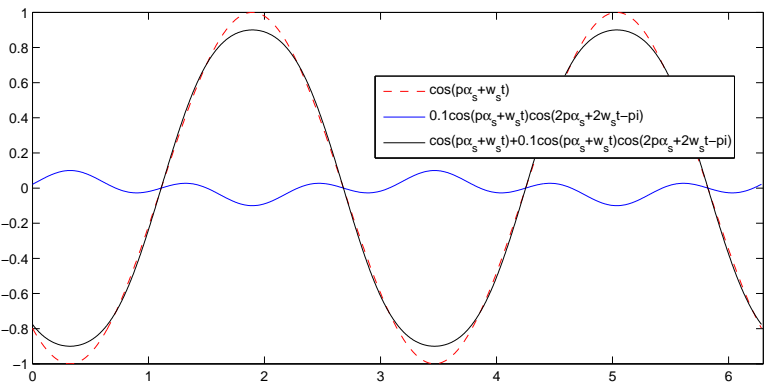

Fig. 1. Illustration of the air-gap radial flux density flattening due to even order saturation permeance waves.

where $\alpha_{r}=\frac{2 \pi f_{s}}{p}(1-s) t$ stands for a rotor bar angular position, $k_{r}$ and $k_{s}$ are strictly positive integers coming from the Fourier development of permeance distribution, and $K_{s r}$ is a multiplicative coefficient proportional to $1 /\left(k_{s} k_{r}\right)$.

Provided that the fundamental stator $\mathrm{mmf}$ is given by $F_{0} \cos \left(p \alpha_{s}-2 \pi f_{s} t\right)$, one can easily find the expression of saturation force waves [13]. The obtained force harmonics are characterized in Table I where strictly positive integers $k_{a}$ come from the Fourier development of saturated permeance distribution, and size the magnitude of permeance harmonics : the highest magnitude force waves are linked to $k_{a}=1$, and $k_{s}=k_{r}=1$. Note that $F_{\text {sat }}^{0}$ saturation vibrations frequencies are the same as some slotting vibrations [4], [18].

TABLE I

MAIN SATURATION FORCE LINES EXPRESSION.

\begin{tabular}{|c|c|c|}
\hline Name & Frequency $f$ & Spatial order $m$ \\
\hline$F_{\text {sat }}^{-}$ & $f_{s}\left(k_{r} Z_{r}(1-s) / p-2\left(1+k_{a}\right)\right)$ & $k_{r} Z_{r}-k_{s} Z_{s}-2 p\left(1+k_{a}\right)$ \\
$F_{\text {sat }}^{0}$ & $f_{s}\left(k_{r} Z_{r}(1-s) / p \pm 2 k_{a}\right)$ & $k_{r} Z_{r}-k_{s} Z_{s} \pm 2 p k_{a}$ \\
$F_{\text {sat }}^{+}$ & $f_{s}\left(k_{r} Z_{r}(1-s) / p+2\left(1+k_{a}\right)\right)$ & $k_{r} Z_{r}-k_{s} Z_{s}+2 p\left(1+k_{a}\right)$ \\
\hline
\end{tabular}

As an example, for $Z_{r}=38, Z_{s}=48$ and $p=2$ the highest saturation force harmonics are given by Table II. However, all the force harmonics of orders superior to 10 will create low magnitude vibrations, so the only important saturation force harmonic is $F_{\text {sat }}^{+}$with order 2 .

TABLE II

MAIN SATURATION FORCE LINES EXPRESSION OF TESTED MOTOR.

\begin{tabular}{|c|c|c|}
\hline Name & Frequency $f$ & Spatial order $m$ \\
\hline$F_{\text {sat }}^{-}$ & $f_{s}\left(Z_{r}(1-s) / p-4\right)$ & -16 \\
$F_{\text {sat }}^{0}$ & $f_{s}\left(Z_{r}(1-s) / p-2\right)$ & -14 \\
$F_{\text {sat }}^{0}$ & $f_{s}\left(Z_{r}(1-s) / p+2\right)$ & -10 \\
$F_{\text {sat }}^{+}$ & $f_{s}\left(Z_{r}(1-s) / p+4\right)$ & -2 \\
\hline
\end{tabular}

\section{Experimental validation}

An operational deflection shape (ODS) is run on a selfventilated squirrel-cage induction machine with $Z_{r}=38$, $Z_{s}=48$ and $p=2$ in order to visualize its stator vibrations. The visualised shape at frequency $f_{s}\left(Z_{r}(1-s) / p+4\right)$ is presented in Fig. 2. In agreement with Table II, an elliptical vibration is observed. This vibration resonates with the stator elliptical mode during starting phase when $f_{s}=f_{2} /\left(Z_{r}(1-\right.$
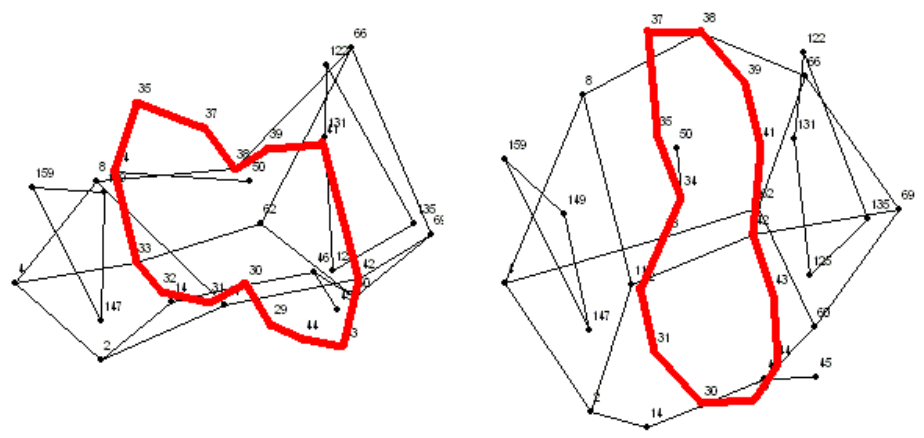

Fig. 2. Deflection shape of tested motor at $f_{s}(38 / 2+4)=23 f_{s}$, with $f_{s}=30 \mathrm{~Hz}$ (no load case), captured at two succesive moments.

$s) / p+4)$, where $f_{2}$ is the stator elliptical mode natural frequency.

The effect of saturation level on noise has also been investigated by progressively increasing the air-gap flux $\phi_{g}$ at the fixed supply frequency where the saturation force wave excites stator elliptical mode. Results are displayed in Fig. 3.

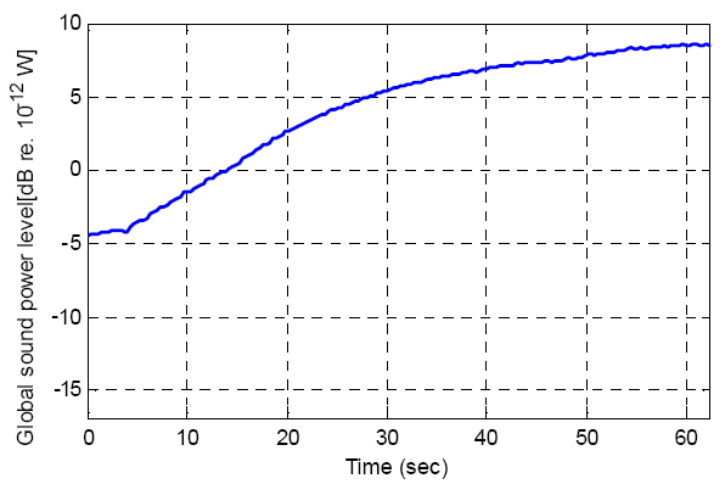

Fig. 3. Normalized evolution of sound power level due to saturation with time, when linearly increasing the air-gap flux from 2 to $7.5 \mathrm{~V} / \mathrm{Hz}$.

An empirical law has therefore been established to quantify the effect of saturation level on noise:

$$
L_{w} \approx \alpha \log _{10}\left(\phi_{g}\right)+\beta
$$

where $\alpha$ and $\beta$ coefficients depend on the motor geometry, and iron magnetization curve (in tested motor, $\alpha=22$ ). This law is useful for predicting how the maximum sound power level encountered during starting will be reduced using a lower air-gap flux.

\section{Reduction of noise due to saturation}

$Z_{r}$ and $Z_{s}$ are both involved in the expressions of saturation forces orders, their choice is therefore highly important to avoid saturation resonances. The great influence of slot combination as already been studied regarding magnetic noise due to slotting vibrations [19].

More precisely, the stator elliptical mode is the most dangerous one in traction motors, so one should avoid to excite this mode with high magnitude saturation vibrations during the whole starting phase (for $p=2, f_{s}$ typically 
goes from 0 to $100 \mathrm{~Hz}$ ). In variable-speed applications, this is more easily done by avoiding to create any saturation force wave of order 2, than trying to avoid frequency match between saturation waves exciting frequencies and elliptical mode natural frequency.

Consequently, $Z_{r}$ and $Z_{s}$ should be chosen so that the largest saturation vibration (given by $k_{a}=k_{r}=k_{s}=1$ ) has not a spatial order of 2 , that is to say

$$
\left|Z_{r}-Z_{s} \pm 2 p, 4 p\right| \neq 2
$$

Tested motor does not respect this rule as $|38-48+4 \times 2|=$ 2 . To respect this rule, a new rotor slot number can be chosen, for instance $Z_{r}=36$. One can easily check that this new slot number satisfies equation (9). In the next part, some simulation and experiments are run in order to check if this new number of rotor slots decrease saturation noise.

\section{SimUlation RESULTS AND EXPERIMENTAL VALIDATION}

\section{A. Simulation results}

Some simulation are run using a simulation tool called DIVA [13], which is able to determine the acoustic noise of magnetic source emitted by an induction machine, including load, pulsewidth modulation (PWM) and saturation effects. This vibroacoustic simulation software has been already validated on several motors [11], [20], [21], [22], [23] and at different stages by tests and finite element method (FEM). More details about the electrical model and vibro-acoustic models used in DIVA are given in those references, and especially how to compute the stator natural frequencies.

The magnitude of saturation permeance harmonics has been validated first with FEM software OPERA. The evolution of the saturated permeance harmonics magnitude with saturation was correct, but the analytical expression (6) did not give results accurate enough, so it has been necessary to introduce a proportional fitting coefficient (see Fig. 4).

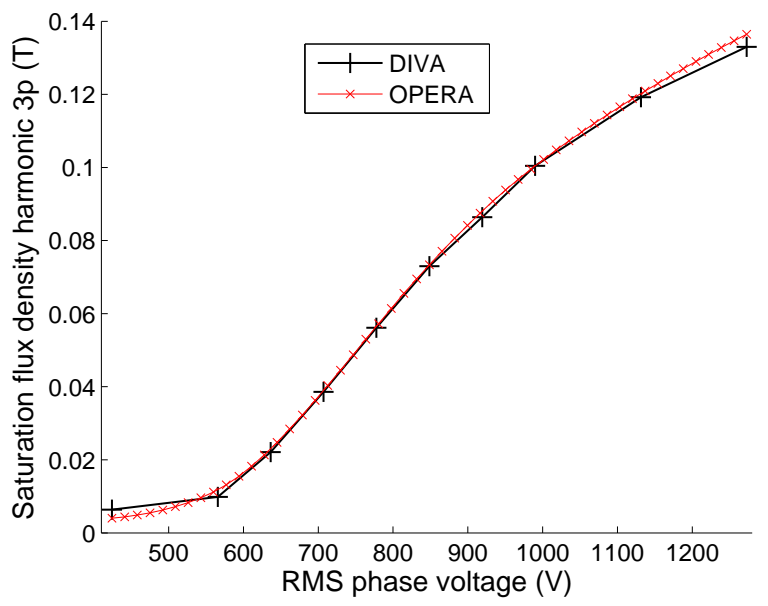

Fig. 4. FEM and DIVA main flux density saturation harmonic of spatial order $3 p$ in function of the applied phase voltage, after having fit the analytical model.

The resulting radial flux density has been also validated with FEM (see Fig. 5).

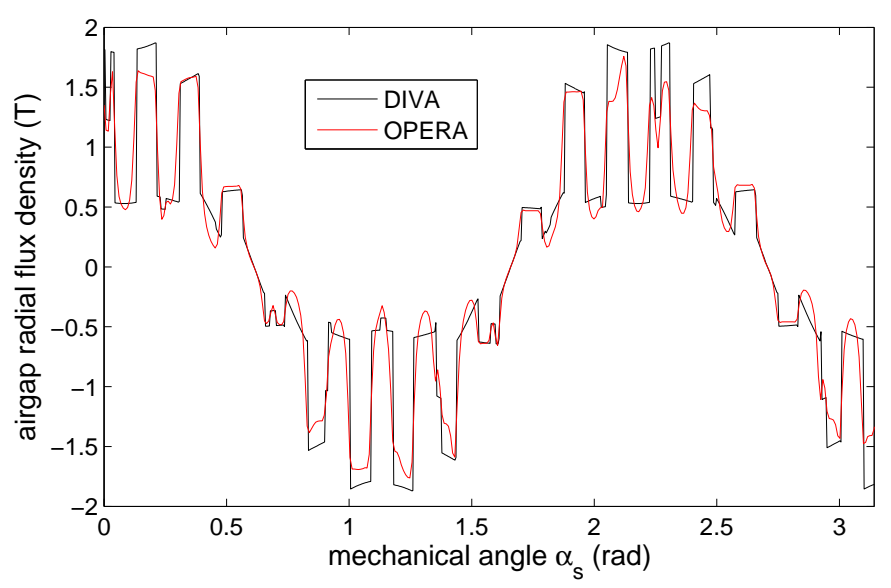

Fig. 5. FEM and DIVA flux density distribution along the air-gap in saturated case.

The variable-speed noise radiated by both tested motor with $Z_{r}=38$ and new proposed motor with $Z_{r}=36$ has been simulated with DIVA (Fig. 6). The actual motor with $Z_{r}=38$ has a strong resonance near $f_{s}=30 \mathrm{~Hz}$, in agreement with both analytical predictions (cf. Table II) and experiments (cf. Fig. 2). The proposed motor does not have any strong magnetic resonance, and theoretically improves the noise level of $20 \mathrm{~dB}$.

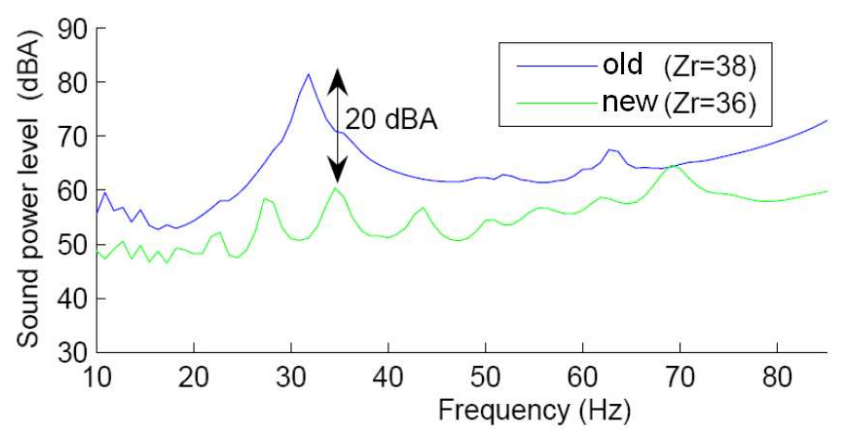

Fig. 6. Sound power level radiated by initial tested motor with $Z_{r}=38$, where a strong saturation vibration resonates with stator elliptical mode, and by proposed motor with a 36 slots rotor.

\section{B. Experimental results}

Fig. 7 presents the noise measurements made on these two different rotors at variable-speed, in off-load sinusoidal case.

As predicted by DIVA model, the 38 slots rotor creates a strong resonance near $35 \mathrm{~Hz}$, whereas no particular resonance is observed on the 36 rotor slots. The new motor noise level nearly evolves linearly with speed: it is now totally covered by fan noise. No noisy saturation vibration occurs, so that a larger saturation level can be used to higher starting torque without increasing magnetic noise level. Furthermore, a $15 \mathrm{~dB}$ on the overall noise (magnetic+aerodynamic) is obtained, against a predicted $20 \mathrm{~dB}$ on magnetic noise only.

\section{Conclusion}

Magnetic noise due to saturation effects in induction machines has been analytically characterized, and these expressions have validated by expriments. They allow to predict 


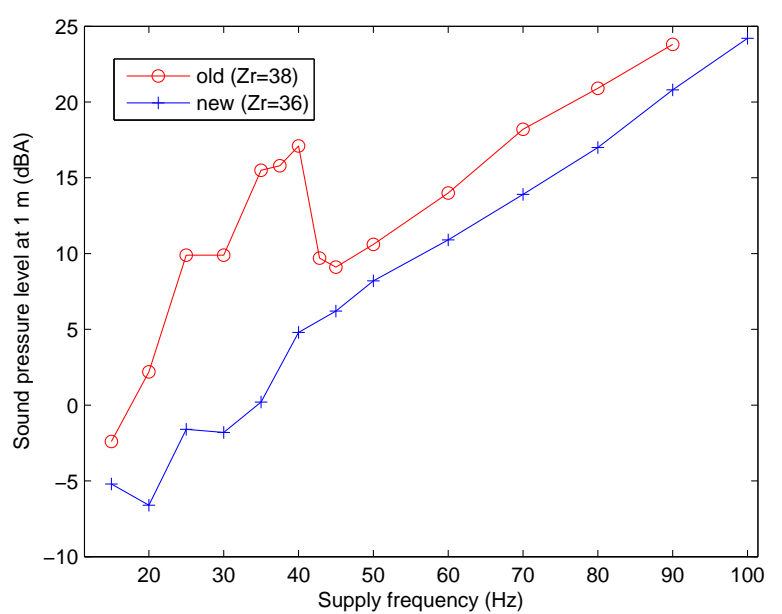

Fig. 7. Sound pressure level radiated by initial motor with $Z_{r}=38$, where a strong saturation vibration resonates with stator elliptical mode, and by the proposed new motor with 36 rotor slots. A normalization factor has been introduced for confidentiality reasons.

possible resonances due to saturation, and a design rule has been proposed to avoid such resonances. This approach has been successfully validated with both simulation results, based on the analytical models, and experiments. A $15 \mathrm{~dB}$ decrease in sinusoidal case has been obtained by simply changing the number of rotor slots in order to avoid resonances due to Maxwell saturation forces.

\section{REFERENCES}

[1] A. Belhacen, "Vibrations of rotating electrical machines due to magnetomechanical coupling and magnetostriction," IEEE Trans. on Magnetics, vol. 42, no. 4, Apr. 2006.

[2] T. Hilgert, A. Vandevelde, and J. Melkebeek, "Numerical analysis of the contribution of magnetic forces and magnetostriction to the vibrations in induction machines," IET Sci. Meas. Technol., vol. 1, no. 1, 2007.

[3] P. Alger, Induction machines : their behaviour and uses. Gordon and Breach Science Publishers, 1970.

[4] P. Timar, Noise and vibration of electrical machines. Elsever, 1989.

[5] H. Jordan, Electric motor silencer - formation and elimination of the noises in the electric motors. W. Giradet-Essen editor, 1950.

[6] S. J. Yang, Low noise electrical motors. Oxford: Clarendon Press, 1981.

[7] W. Soedel, Vibrations of shells and plates. Marcel Dekker, 1993.

[8] S. Verma and A. Balan, "Determination of radial-forces in relation to noise and vibration problems of squirrel-cage induction motors," IEEE Trans. on En. Conv., vol. 9, no. 2, June 1994.

[9] G. Bossio, C. D. Angelo, J. Solsona, G. Garcia, and M. Valla, "A 2-D model of the induction machine: an extension of the modified winding function approach," IEEE Trans. on Energy Conversion, vol. 19, no. 1, Mar. 2004.

[10] M. Poloujadoff, "General rotating mmf theory of squirrel cage induction machines with non-uniform air gap and several non sinusoidally distributed windings," IEEE Trans. on P.A.S, vol. 101, no. 3, Mar. 1982.

[11] J. L. Besnerais, V. Lanfranchi, M. Hecquet, P. Brochet, and G. Friedrich, "Acoustic noise of electromagnetic origin in a fractional-slot induction machine," COMPEL, vol. 27, no. 5, Feb. 2008.

[12] W. Lo, C. Chan, Z. Zhu, L. Xu, D. Howe, and K. Chau, "Acoustic noise radiated by $\mathrm{PWM}$-controlled induction machine drives," IEEE Trans. on Industrial Electronics, vol. 47, no. 4, Aug. 2000.

[13] J. L. Besnerais, "Reduction of magnetic noise in PWM-supplied induction machines - low-noise design rules and multi-objective optimisation," Ph.D. dissertation, Ecole Centrale de Lille, France, Nov. 2008.

[14] K. Maliti, "Modelling and analysis of magnetic noise in squirrel-cage induction motors," Ph.D. dissertation, Stockholm, 2000.
[15] J. Moreira and T. Lipo, "Modeling of saturated AC machines including air gap flux harmonics components," IEEE Trans. on Ind. Appl., vol. 28, 1992.

[16] H. Frohne, "ber die primren Bestimmungsgr $\beta$ en der Lautstrke bei Asynchronmaschinen,” Ph.D. dissertation, Hannover, Germany, 1959.

[17] J. Brudny, "Modélisation de la denture des machines asynchrones : phénomènes de résonances," Journal of Physics III, vol. 37, no. 7, 1997.

[18] H. D. Gersem, K. Hameyer, and T. Weiland, "Electromagnetically excited audible noise in electrical machines," IEEE Trans. on Magnetics, vol. 39, no. 3, May 2003.

[19] T. Kobayashi, F. Tajima, M. Ito, and S. Shibukawa, "Effects of slot combination on acoustic noise from induction motors," IEEE Trans. on Mag., vol. 33, no. 2, 1997.

[20] J. L. Besnerais, V. Lanfranchi, M. Hecquet, and P. Brochet, "Multiobjective optimization of induction machines including mixed variables and noise minimization," IEEE Trans. on Mag., vol. 44, no. 6, June 2008.

[21] J. L. Besnerais, V. Lanfranchi, M. Hecquet, P. Brochet, and G. Friedrich, "Characterisation of the radial vibration force and vibration behaviour of a PWM-fed fractional-slot induction machine," IET, Nov. 2008.

[22] J. L. Besnerais, V. Lanfranchi, M. Hecquet, and P. Brochet, "Characterization of the audible magnetic noise emitted by traction motors in railway rolling stock," in Proc. of the INTERNOISE conference, Shanghai, China, Oct. 2008.

[23] J. L. Besnerais, A. Fasquelle, J. Pelle, S. Harmand, M. Hecquet, V. Lanfranchi, P. Brochet, and A. Randria, "Multiphysics modeling: electro-vibro-acoustics and heat transfer of induction machines," in Proc. of the International Conference on Electrical Machines (ICEM'08), Villamura, Portugual, Sept. 2008. 